\title{
Effectiveness of zinc-fortified water on zinc intake, status and morbidity in Kenyan pre-school children: a randomised controlled trial
}

\author{
Prosper Kujinga ${ }^{1, *} \dagger$, Valeria Galetti ${ }^{2}$, Elizabeth Onyango ${ }^{3}$, Viktor Jakab², \\ Simone Buerkli ${ }^{2}$, Pauline Andang' ${ }^{4}{ }^{4}$, Inge D Brouwer ${ }^{1}$, Michael B Zimmermann ${ }^{2}$ and \\ Diego Moretti ${ }^{2, *}$ \\ 'Division of Human Nutrition, Wageningen University, PO Box 8129, EV Wageningen 6700, The Netherlands: \\ ${ }^{2}$ Laboratory of Human Nutrition, Institute of Food, Nutrition and Health, ETH Zurich, Schmelzbergstrasse 7, \\ Zurich 8092, Switzerland: ${ }^{3}$ School of Nursing, Midwifery and Paramedics, Masinde Muliro University of \\ Science and Technology, Kakamega, Kenya: ${ }^{4}$ School of Public Health and Community Development, \\ Department of Nutrition, Maseno University, Maseno, Kenya
}

Submitted 28 November 2017: Final revision received 24 April 2018: Accepted 4 May 2018: First published online 7 June 2018

\begin{abstract}
Objective: $\mathrm{Zn}$ deficiency and diarrhoea are prevalent and may coexist in children living in low-resource settings. Recently, a novel approach for delivering $\mathrm{Zn}$ via microbiologically treated, Zn-fortified water was shown to be effective in improving Zn status in West African schoolchildren. We assessed the effectiveness of Zn-fortified, microbiologically purified water delivered as a household intervention on $\mathrm{Zn}$ intake, status and morbidity in children aged 2-6 years from rural western Kenya.

Design: Randomised controlled trial. Intervention included households assigned to water treatment device with (ZFW) or without (FW) Zn delivery capability

Setting: Rural households in Kisumu, western Kenya.

Subjects: Children aged 2-6 years.

Results: The ZFW group had higher dietary Zn intake compared with the FW group. ZFW contributed 36 and $31 \%$ of daily requirements for absorbable $\mathrm{Zn}$ in children aged 2-3 and 4-6 years, respectively, in the ZFW group. Consumption of Zn-fortified water resulted in lower prevalence of reported illness (risk ratio; 95\% CI) in the ZFW group compared with the FW group: for cold with runny nose $(0.91 ; 0.83,0.99$; $P=0.034)$ and abdominal pain $(0.70 ; 0.56,0.89 ; P=0.003)$ in the intention-to-treat analysis and for diarrhoea $(0.72 ; 0.53,0.96 ; P=0.025)$ in the per-protocol analysis. We did not detect an effect of treatment on plasma Zn concentration.

Conclusions: Daily consumption of Zn-fortified, microbiologically treated water results in increased intake of absorbable dietary $\mathrm{Zn}$ and may help in preventing childhood infections in pre-school children in rural Africa.
\end{abstract}

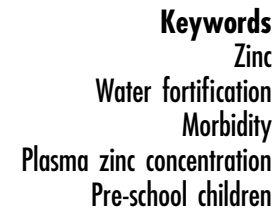

The WHO estimates that $17 \%$ of the world's population is at risk of $\mathrm{Zn}$ deficiency ${ }^{(1)}$, with prevalence estimates highest in sub-Saharan Africa, particularly among children ${ }^{(2)}$. Zn deficiency is associated with growth deficits, compromised immunity and higher risk of gastrointestinal and respiratory tract infections. A common cause of $\mathrm{Zn}$ deficiency is the habitual consumption of foods low in bioavailable Zn. A contributing factor may also be high $\mathrm{Zn}$ losses caused by

$\uparrow$ Current address: Faculty of Science, Department of Food and Nutrition Science, University of Zimbabwe, PO Box MP167, Mt Pleasant, Harare, Zimbabwe. frequent diarrhoea episodes ${ }^{(2)}$. In settings where diarrhoea is endemic, $\mathrm{Zn}$ deficiency often coexists ${ }^{(3)}$.

Preventive $\mathrm{Zn}$ supplementation improves plasma $\mathrm{Zn}$ (PZn) status and decreases morbidity due to diarrhoea ${ }^{(4)}$. There is a lack of evidence on the effectiveness of $\mathrm{Zn}$ fortification on growth and morbidity in children ${ }^{(5)}$, which has been attributed to factors such as the choice of fortificant, food vehicle ${ }^{(6)}$ and excessive $\mathrm{Zn}$ losses ${ }^{(3)}$. A promising approach for delivering $\mathrm{Zn}$ in diarrhoea-endemic, $\mathrm{Zn}$ deficient communities is through microbiologically purified Zn-fortified water. Zn from drinking-water consumed away 
from meals is highly absorbed to the absence of absorptioninhibitory dietary components such as phytate ${ }^{(7)}$.

In a proof-of-concept study, a household filtration device simultaneously removing microbiological contamination and fortifying water with $\mathrm{Zn}$ from $\mathrm{ZnO}$ embedded in phosphate-based glass plates at a concentration of $\approx 8 \mathrm{mg} / \mathrm{l}$ has been reported to be effective in improving $\mathrm{Zn}$ status in a randomised controlled trial in school-aged children in northern Benin ${ }^{(7)}$. This water filtration and fortification system has been described in full elsewhere ${ }^{(7)}$. We aimed to quantify the effectiveness of the same household water treatment device as a home-based intervention in pre-school children, a high-risk group for gastrointestinal and respiratory infections in resource-poor settings. We assessed its impact on $\mathrm{Zn}$ intake, $\mathrm{Zn}$ status and morbidity in a 6-month, prospective, double-blind, randomised controlled trial in a lowincome area exposed to unimproved water in rural Kenya.

\section{Methods}

\section{Study setting, design and randomisation}

The present study was conducted between February 2014 and August 2014 in western Kenya, Kisumu West District. The study area consisted of fifteen villages in the sublocation Kajulu Koker located along the shores of Lake Victoria. This rural population lacks access to many basic health-care services and poverty is prevalent. The estimated literacy rate in women 15 years old or above is $90 \cdot 8 \%^{(8)}$. The study population relies on water from Lake Victoria or rainwater for domestic purposes, with main economic activities being small-scale farming and fishing. Western Kenya has a tropical climate with two rainy seasons, typically taking place as long rains from March to May and as short rains from October to December.

Eligible study households were randomly assigned to two groups using the household listing and the random function on Microsoft ${ }^{\circledR}$ Excel version 14 (2010). The randomisation was repeated until groups were comparable in anthropometric, demographic and haematological parameters. One child aged 2-6 years was enrolled per eligible household; when there was more than one child between 2 and 6 years old, only one of them was randomly selected to participate. The control group received a normal water purification filter which did not deliver $\mathrm{Zn}$ (FW), while the intervention group received a purification filter containing Zn-delivery glass plates (ZFW). Control and intervention filters were identical in presentation and were weight-matched. Randomisation was performed by a member of the investigating team who was not present at screening and enrolment, nor was involved in data analysis. All study personnel and participants were blinded to treatment assignment for the duration of the study. Number codes were used to identify the two treatment arms. Treatment assignment (the code) was revealed to the investigators at the end of primary and secondary analysis.

\section{Study population}

Children were enrolled into the study if they were aged 2-6 years, residing in Kajulu Koker, apparently healthy, with $\mathrm{Hb}$ concentration $>70 \mathrm{~g} / \mathrm{l}$. Children were excluded if they were chronically ill or were participating in other clinical trials in the area.

\section{Dietary intake and water consumption}

Dietary intake in 112 children was assessed using a quantitative multi-pass $24 \mathrm{~h}$ recall method $^{(9)}$ for all seven days, with all recall days evenly distributed throughout the week, and repeated for each child on a non-consecutive day to permit adjustment for day-to-day variation. The sample size was estimated to be adequate to determine a mean daily $\mathrm{Zn}$ intake deviating less than $0.3 \mathrm{mg}$ from the true intake with $80 \%$ power and $95 \%$ confidence, assuming an expected mean intake of $2.8 \mathrm{mg} / \mathrm{d}$ with an anticipated SD of $1.5 \mathrm{mg} / \mathrm{d}^{(10,11)}$. Caregivers were informed of the visits but not the exact day they would be interviewed. The interviews were carried out by local, trained interviewers fluent in speaking Dholuo language. Children were randomly allocated to day of the week, interviewers were randomly allocated to households and repeated household visits by the same interviewer were avoided. Caregivers were first asked to list all the foods and drinks the child had consumed at home and away in the previous $24 \mathrm{~h}$ from waking up the day before the interview until waking up the day of interview. Then they were requested to mention all the ingredients and cooking methods for each food/dish. Duplicate amounts of all foods, beverages and ingredients were weighed to the nearest $1 \mathrm{~g}$ using a digital precision balance scale (Kern EMB, Germany). If duplicate amounts were not available in the household during the interview, amounts were estimated using household units, such as volume (such as using a cup), size (small, medium, large) or as monetary equivalents. Conversion factors were determined by the supervisors and these were used to determine the amount consumed by the child. Caregivers were systematically probed for any food, beverage or snack omitted during the interview. Standard recipes were generated to estimate the amount of ingredients consumed from mixed dishes purchased or eaten outside the home by averaging three recipes of different caregivers or vendors in the local area. For foods consumed at school, crèche or day care, recipes were collected from the school cook. In all cases, the proportion given to child was calculated as the total volume given to the child minus any leftovers divided by the total volume of food cooked by the caregiver/vendor/school cook. This proportion was multiplied by the total amount of ingredients used in preparing the dish to determine the amount consumed by the child.

Consumption of both unfiltered and filtered water was assessed for each child during the 25 weeks of the intervention. Study children were provided with cups of 
standard $300 \mathrm{ml}$ volume graduated at 75,150 and $300 \mathrm{ml}$. A personal diary was filled out by each caregiver every day to record the participating child's water intake by placing a tally mark under the image corresponding to the day of week, type of water consumed and administered volume whenever the index child consumed water. The personal diaries using tallies were the most reliable method out of four other methods (tally counter, $24 \mathrm{~h}$ recall, graduated water jug, observation) tested in a pilot study ${ }^{(12)}$.

For PZn determination, a total sample size of 180 children in total was determined sufficient to detect a difference in PZn of $5 \mu \mathrm{g} / \mathrm{dl}$ assuming an SD of $9 \mu \mathrm{g} / \mathrm{dl}$ at a two-tailed $5 \%$ significance level with $80 \%$ power and an attrition rate of $20 \%$.

\section{Blood collection and biochemical analysis}

All blood samples were collected between 08.00 and 13.00 hours from fasting and non-fasting child participants for PZn analysis according to the International Zinc Nutrition Consultative Group protocol ${ }^{(13)}$ at baseline, 3 months and 6 months. Samples were collected in different communities using a central location as sampling site (school or health centre). Venous blood was drawn into a trace-element-free lithium heparin tube (Monovettes; Sarstedt system tubes, Numbrecht, Germany) and placed in a cooler box. To avoid endogenous and exogenous contamination we adhered to the standardised sampling and processing protocols recommended by the International Zinc Nutrition Consultative Group $^{(13)}$. To obtain plasma, blood was centrifuged at $3000 \mathrm{rpm}$ for $10 \mathrm{~min}$ using a field centrifuge within $40 \mathrm{~min}$ from collection. Time of blood collection and time of the last meal were recorded in field log sheets. Plasma samples were stored at $-20^{\circ} \mathrm{C}$ until analysis. $\mathrm{Hb}$ was analysed in the field using a HemoCue photometer (HemoCue HB 201, Sweden). Plasma Zn was measured at ETH Zurich, Switzerland by atomic absorption spectrometry (AA240FS; Varian Inc., Australia) as previously described ${ }^{(7)}$. C-reactive protein and $\alpha_{1}$-acid glycoprotein (AGP) were analysed using sandwich ELISA at a laboratory in Freiburg, Germany ${ }^{(14)}$. We coded specimens from all time points and analysed them without knowledge of study arm and in a random order. All values represent the mean of an independent duplicate measurement. We re-ran analysis if the $\mathrm{CV}$ exceeded $5 \%$ and removed obvious outliers. We calculated prevalence of low PZn by using the time of day- and age-specific lower cut-offs of the International Zinc Nutrition Consultative Group ${ }^{(2)}$. Subclinical inflammation was defined as C-reactive protein $>5 \mathrm{mg} / \mathrm{l}$ and/or AGP $>1 \mathrm{~g} / \mathrm{l}$. Anaemia was defined as $\mathrm{Hb}<110 \mathrm{~g} / \mathrm{l}$ in children aged $0.5-4.9$ years and as $\mathrm{Hb}<115 \mathrm{~g} / \mathrm{l}$ in children aged 5 years or older ${ }^{(15)}$.

\section{Anthropometry}

At baseline, midpoint and endpoint, weight and height were measured according to WHO guidelines to the nearest $0.1 \mathrm{~kg}$ and $0.1 \mathrm{~cm}$, respectively, using an electronic scale (Ashton Meyers, UK) and a UNICEF wooden measuring board with a sliding head piece. Measurements were taken twice and values represent the mean of duplicate measurements. The accuracy of the weighing scale was checked daily with a known weight. The same research assistant took the measurements at the three time points. Age was calculated using verifiable records (birth certificate, health record) or estimated based on a traditional calendar. $Z$-scores for height-forage (HAZ) and weight-for-age (WAZ) were determined for each child using WHO ANTHRO PLUS software version 1.0.4. Children were classified as stunted or underweight if their HAZ or WAZ, respectively, was less than -2 .

\section{Morbidity}

Prevalence of diarrhoea and other symptoms (upper respiratory infection, rapid breathing, cough, abdominal pain, fever, headache) in the study children was assessed weekly by field assistants who completed a forced-choice questionnaire by interviewing the caregivers. The recall period for symptoms was 1 week, except for diarrhoea, where a recall period of $48 \mathrm{~h}$ was applied ${ }^{(16)}$. Diarrhoea was defined using the WHO definition of three or more loose stools passed in $24 \mathrm{~h}^{(17)}$. Clinic visit records when available were asked for proof to verify symptoms reported.

\section{Monitoring device usage and effectiveness}

All households were provided with a tally counter to record each time they refilled one jerry can (10 litres) with filtered water. During the weekly visit by the field assistant, the number on the tally counter was recorded and set back to zero. One count was assumed to be equal to one filtering event of 10 litres. Device effectiveness was assessed by measuring $\mathrm{Zn}$ content in effluent water samples from thirty-five randomly selected households representing $19 \%$ of the study households (eighteen from the ZFW group, seventeen from the FW group). Water was sampled for $\mathrm{Zn}$ analysis by atomic absorption spectrometry at the Laboratory for Human Nutrition, ETH Zurich, Switzerland at four random time points over the intervention period.

\section{Data analysis}

Dietary zinc intake

Compl-eat ${ }^{\Theta}$ version 1.0 (Wageningen University, the Netherlands) was used to calculate $\mathrm{Zn}$ and energy intakes from the $24 \mathrm{~h}$ recalls. Nutrient intake calculations were based on a food composition table developed specifically for the study using the Kenya national food composition table as primary source ${ }^{(18)}$. US Department of Agriculture retention factors ${ }^{(19)}$ were applied to raw ingredients and foods to account for nutrient losses during food 
preparation. Nutrient intake analysis was done using the statistical software package IBM SPSS Statistics version 21. Normality of distributions was tested by visually comparing the sample distribution with a standard normal distribution using quantile-quantile (Q-Q) plots. Non-normal nutrient intake data were log-transformed, resulting in normal distributions, and then back-transformed to facilitate interpretation. All nutrient intakes were adjusted for day-to-day variation according to the method developed by the National Research Council ${ }^{(20)}$. The percentage of children below the WHO Estimated Average Requirement for children aged $1-3$ years $(6.9 \mathrm{mg} / \mathrm{d})$ and $4-6$ years $(8.0 \mathrm{mg} / \mathrm{d})$ for $\mathrm{Zn}$ intake was determined, assuming $15 \%$ $\mathrm{Zn}$ bioavailability from food. The contribution that $\mathrm{Zn}$ fortified water made to WHO physiological requirements in children aged $1-3$ years $(0.83 \mathrm{mg} / \mathrm{d})$ and $4-6$ years $(0.97 \mathrm{mg} / \mathrm{d})$ was determined ${ }^{(2)}$.

\section{Intervention effectiveness}

Data were analysed using IBM SPSS Statistics version 21. Normality of distributions was tested visually using Q-Q plots. We excluded outliers, defined as more than $3 \mathrm{SD}$ from the overall mean, at baseline, midpoint and endpoint. One outlier was identified at baseline for PZn $(22.4 \mu \mathrm{g} / \mathrm{dl})$, one at midpoint $(173.4 \mu \mathrm{g} / \mathrm{dl})$ and one at endpoint $(28.0 \mu \mathrm{g} / \mathrm{dl})$. We tested baseline or overall group differences using the independent-samples $t$ test for normally distributed data, the Mann-Whitney $U$ test when the data were non-normal and the sign test for paired non-normal data. The $\chi^{2}$ test was used to test group differences between withdrawal rates. We tested the intervention effect on continuous outcomes and binary outcomes using linear mixed-effect models and generalized estimating equations $^{(21)}$, respectively, with unstructured covariance matrix. Participants were defined as random components,

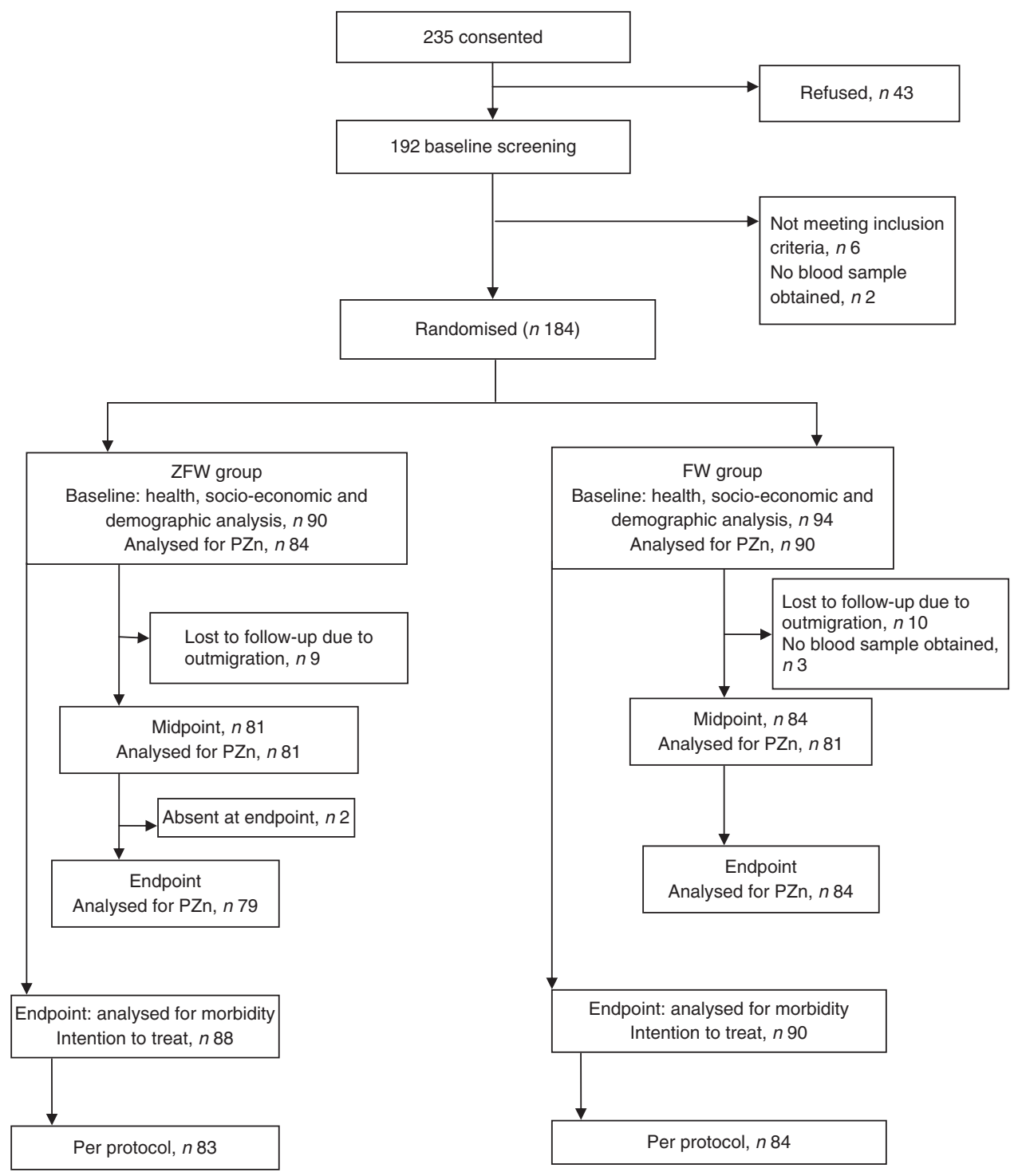

Fig. 1 Trial profile (ZFW, zinc-fortified filtered water; FW, filtered water; PZn, plasma zinc) 
and time, treatment and the time-by-treatment interaction as fixed effects on the variance. Models with different covariates (e.g. fasting status) were compared and we selected the best-fit model by the Akaike information criterion and the Bayesian information criterion. Statistical dependence was tested using the Pearson product-moment correlation coefficient $(r)$ for normally distributed data and with Spearman's rank correlation coefficient $\left(r_{\mathrm{s}}\right)$ for nonnormally distributed data. Risk ratios (RR) and 95\% CI for disease incidence were calculated by means of Ken Rothman Epi Sheet (http://www.epidemiolog.net/studymat/), which compared the number of visits with reported events with the total number of visits. The significance level was set at $P<0.05$. Compliance to treatment was defined as median water consumption $>500 \mathrm{ml} / \mathrm{d}$. The primary analysis was intention to treat and included all children enrolled at baseline. Per-protocol analysis was restricted to children who completed 25 weeks of the trial.

\section{Results}

Participants were recruited from 31 January 2014 until 14 February 2014. In total, 235 caregivers initially consented to the study on behalf of the children. After forty-three refusals between consenting and baseline, 192 were screened. Of these, six had severe anaemia and two phlebotomies were unsuccessful. Thus, a total of 184 children were included in the study and randomised to the intervention or control group. The study was completed by 167 children with a dropout rate of $9 \cdot 2 \%$ (Fig. 1) and no significant difference in withdrawals between the ZFW group ( $8.0 \%)$ and FW group (10.6\%; $P<0.05)$. One of the main reasons for non-completion of the trial was migration out of the study area.

ZFW and FW participants were not different at baseline in demographic, socio-economic characteristics and nutritional status (Table 1). Similarly, there was no difference in baseline dietary $\mathrm{Zn}$ intake with no drinking-water added (6.0 (sD 1.7) mg/d $v .5 .7$ (sD 1.6) $\mathrm{mg} / \mathrm{d} ; P=0.37$; Table 2) or energy intake (6146 (sD 1385) kJ/d (1469 (sD 331 ) kcal/d) v. 6343 (sD 1222) kJ/d (1516 (sD 292) kcal/d; $P=0.43)$, or in the proportion of participants below the WHO age-specific Estimated Average Requirement for $\mathrm{Zn}$ intake, being 81.1 and $87.3 \%(P=0 \cdot 41)$ in the ZFW group and FW group, respectively. Similarly, there was no difference in compliance (39 and $42 \%$ for $\mathrm{ZFW}$ and $\mathrm{FW}$ group, respectively) between the two groups during the intervention $(P=0.63)$.

Median device usage was 3 (interquartile range (IQR) 2-5) filtration events per week for households of both groups (Fig. 2). Median unfiltered water intake was 0 (IQR $0-0) \mathrm{ml} / \mathrm{d}$ and did not differ between groups $(P=0 \cdot 17)$. There was an overall slight decrease of filtration events over time $(P<0 \cdot 001)$. Notable peaks of increase in filter usage were observed at the start of the intervention, midpoint and endpoint. Median filtered water intake for ZFW and FW groups was 450 (IQR 289-675) ml/d and 471 (IQR 300-718) $\mathrm{ml} / \mathrm{d}$, respectively, over the intervention period with no significant difference between the two groups $(P=0 \cdot 17)$. Water treatment devices were effective $(P<0.01)$ in delivering higher $\mathrm{Zn}$ concentration in $\mathrm{ZFW}-$ group water samples $(n 74)$, median 1.0 (IQR $0 \cdot 5-2 \cdot 5) \mathrm{mg}$ $\mathrm{Zn} / \mathrm{l}$, compared with the FW group ( $n 76$ ), median 0.3 (IQR 0·1-0.6) $\mathrm{mg} \mathrm{Zn/l} \mathrm{(Fig.} \mathrm{3).} \mathrm{Median} \mathrm{Zn}$ intake from filtered water was 0.5 (IQR 0.3-0.6) $\mathrm{mg} \mathrm{Zn/d}$ for the $\mathrm{ZFW}$ group and $0.0(\mathrm{IQR} 0 \cdot 0-0 \cdot 1) \mathrm{mg} \mathrm{Zn} / \mathrm{d}$ for the FW group (Table 2 and Fig. 3). Zn-fortified water at an absorption rate of $65.9 \%{ }^{(7)}$ contributed 36 and $31 \%$ of the WHO daily requirements for absorbable $\mathrm{Zn}$ in children aged $2-3$ years $(0.83 \mathrm{mg} / \mathrm{d})$ and $4-6$ years $(0.97 \mathrm{mg} / \mathrm{d})$, respectively ${ }^{(2)}$.

There was no significant time-by-treatment effect on uncorrected PZn $(P=0 \cdot 11)$ nor on the prevalence of $\mathrm{Zn}$ deficiency $(P=0.51$; Tables 3 and 4$)$. There was a trend towards a time effect $(P=0.07)$ and a significant positive time-by-treatment interaction effect on the prevalence of elevated AGP $(P=0 \cdot 019)$, with the ZFW group having generally higher levels of AGP than the FW group. There was no significant time effect $(P=0.69)$ or time-bytreatment effect on HAZ $(P=0.97)$ or prevalence of stunting $(P=0 \cdot 88)$.

There were lower numbers of occasions of reported cold with runny nose $(\mathrm{RR}=0.91 ; 95 \%$ CI $0.83,0.99$; $P=0.034)$, abdominal pain ( $\mathrm{RR}=0.70 ; 95 \% \mathrm{CI} 0.56,0.89$; $P=0.003)$ and a trend for diarrhoea $(\mathrm{RR}=0.78 ; 95 \% \mathrm{CI}$ $0.59,1.04 ; P=0.09$ ) in the ZFW group compared with the FW group. Per-protocol analysis showed similar results, except for reported diarrhoea which was significantly lower in the ZFW group, $3.6 \%(73 / 2022)$, than in the FW group, $5.0 \%(103 / 2043 ; \mathrm{RR}=0.72 ; 95 \%$ CI $0.53,0.96$; $P=0.03$; Table 5).

\section{Discussion}

We investigated the effect of Zn-fortified water on $\mathrm{Zn}$ intake and morbidity in young rural Kenyan children. Consumption of fortified water over a 25 -week intervention period increased daily $\mathrm{Zn}$ intake. This was associated with lower morbidity due to abdominal pain and upper respiratory tract infection, and a trend towards lower reports of diarrhoea which was significant in the perprotocol analysis. Our findings build upon a previous study demonstrating the efficacy of Zn-fortified water to increase $\mathrm{Zn}$ status in schoolchildren ${ }^{(7)}$ in a controlled school setting, where water portions were administered under close supervision. Our current study was designed as an 'effectiveness' household-based trial, under similar conditions to real life: filtering devices were distributed to the households and participants were responsible for operating the water treatment device, such as in a donordriven initiative. By the nature of the effectiveness 
Table 1 Demographic, socio-economic and nutritional status of the study children aged 2-6 years from rural western Kenya, February-August 2014

\begin{tabular}{|c|c|c|c|c|}
\hline \multirow[b]{2}{*}{ Variable assessed } & \multicolumn{2}{|c|}{ ZFW group } & \multicolumn{2}{|c|}{ FW group } \\
\hline & $n$, Median, Mean or $\%$ & IQR or SD & $n$, Median, Mean or $\%$ & IQR or SD \\
\hline$n$ & 90 & - & 94 & - \\
\hline Age (months)* & 47 & $37-57$ & 46 & $36-59$ \\
\hline Sex male (\%) & 43 & - & 48 & - \\
\hline \multicolumn{5}{|l|}{ Nutritional status $†$} \\
\hline Height-for-age Z-score $¥$ & -0.9 & 1.5 & -0.8 & 1.8 \\
\hline Stunted (\%) & $15 \cdot 9$ & - & 19.5 & - \\
\hline Weight-for-age Z-score $\ddagger$ & -0.1 & 0.9 & -0.1 & 0.9 \\
\hline Underweight (\%) & $7 \cdot 3$ & - & $12 \cdot 2$ & - \\
\hline \multicolumn{5}{|c|}{ Socio-economic characteristics of households } \\
\hline Household size* & 6 & $4-7$ & 6 & $5-7$ \\
\hline \multicolumn{5}{|l|}{ Main source of income§ } \\
\hline Casual labour (\%) & $51 \cdot 7$ & - & $56 \cdot 7$ & - \\
\hline Fishing (\%) & $25 \cdot 8$ & - & $15 \cdot 5$ & - \\
\hline Other\| $(\%)$ & $23 \cdot 3$ & - & $27 \cdot 8$ & - \\
\hline \multicolumn{5}{|c|}{ Drinking-water source (wet season) } \\
\hline Rain harvesting (\%) & 91.0 & - & $89 \cdot 4$ & - \\
\hline Lake Victoria (\%) & 7.9 & - & 7.4 & _- \\
\hline Other $(\%)$ & $1 \cdot 1$ & - & $3 \cdot 2$ & - \\
\hline \multicolumn{5}{|c|}{ Drinking-water source (dry season) } \\
\hline Lake Victoria (\%) & 53.3 & - & 53.2 & - \\
\hline Public tap (\%) & $17 \cdot 8$ & - & $18 \cdot 1$ & - \\
\hline Private well, protected (\%) & $14 \cdot 4$ & - & 14.9 & - \\
\hline Other ${ }^{\star \star}(\%)$ & $14 \cdot 4$ & - & 13.8 & - \\
\hline \multicolumn{5}{|l|}{ Toilet facility } \\
\hline Not shared (\%) & $85 \cdot 6$ & - & $80 \cdot 9$ & - \\
\hline No toilet (\%) & $7 \cdot 8$ & - & 14.9 & - \\
\hline Shared (\%) & $5 \cdot 6$ & - & $2 \cdot 1$ & - \\
\hline Did not respond (\%) & $1 \cdot 1$ & - & $2 \cdot 1$ & - \\
\hline \multicolumn{5}{|l|}{ Type of toilet } \\
\hline Pit latrine without slab (\%) & $60 \cdot 0$ & - & $62 \cdot 8$ & - \\
\hline Pit latrine with slab (\%) & $31 \cdot 1$ & - & $22 \cdot 3$ & - \\
\hline Bush toilet (\%) & $7 \cdot 8$ & - & $12 \cdot 8$ & - \\
\hline Did not respond (\%) & $1 \cdot 1$ & - & $2 \cdot 1$ & - \\
\hline \multicolumn{5}{|l|}{ Transport type } \\
\hline None (\%) & $62 \cdot 0$ & - & 42.5 & - \\
\hline Bicycle (\%) & 33.3 & - & 33.0 & - \\
\hline Motorbike (\%) & 4.4 & - & $9 \cdot 6$ & - \\
\hline Did not respond (\%) & 0.3 & - & 14.9 & - \\
\hline \multicolumn{5}{|l|}{ Fuel source } \\
\hline Wood (\%) & 98.8 & - & $100 \cdot 0$ & - \\
\hline Other†† (\%) & $1 \cdot 1$ & - & 0.0 & - \\
\hline
\end{tabular}

FW, filtered water; ZFW, Zn-fortified filtered water; IQR, interquartile range.

Group-wise differences were analysed by the independent-samples $t$ test and the Mann-Whitney $U$ test for normal and non-normal data, respectively, and the $X^{2}$ test for categorical data. There was no significant difference $(P>0.05)$ between the groups for all variables analysed.

*Values are median and IQR.

† $n 82$ for the ZFW and FW group for height-for-age Z-score only due to missing date of birth. Children with height-for-age Z-score <-2 and weight-for-age $Z$-score $<-2$ were considered stunted and underweight, respectively, according to the WHO growth standards for children aged $<59$ months and the WHO 2007 growth reference for children aged $>60$ months.

$\ddagger$ Values are mean and SD.

$\S$ Multiple responses were possible.

IIncludes crop sales, trade, small business, formal employment and unemployed.

IIncludes private tap, public tap, protected/unprotected well, tank and one non-response.

**Includes private tap, public tap, unprotected well, tank and rain harvesting.

††Includes electricity from solar energy and gas.

intervention, $40 \%$ of the participants consumed on average $500 \mathrm{ml}$ of treated water daily, compared with the closer adherence to the target of $600 \mathrm{ml} \mathrm{water} / \mathrm{d}$ in the Benin trial ${ }^{(7)}$. In addition, the $\mathrm{Zn}$ concentration in the consumed water was limited to average $2.4 \mathrm{mg} / 1 \mathrm{com}$ pared with $\approx 4 \mathrm{mg} / \mathrm{l}$ in the Benin study. In the current study, Zn concentration was limited due to the natural variability in water consumption and possible differences in $\mathrm{Zn}$ elution rates when the device was used in households, where varying usage patterns may have resulted in fluctuating $\mathrm{Zn}$ concentrations. High $\mathrm{Zn}$ concentrations in eluted water would be of concern because Zn may impart an astringent taste to water at concentrations higher than $\approx 4 \mathrm{mg} / \mathrm{l}^{(22)}$. The International Zinc Nutrition Consultative Group has set revised Tolerable Upper Intake Levels for $\mathrm{Zn}$ intake in children aged $2-3$ years and $4-6$ years, namely 8 and $14 \mathrm{mg} / \mathrm{d}$, respectively ${ }^{(2)}$. 
(a)

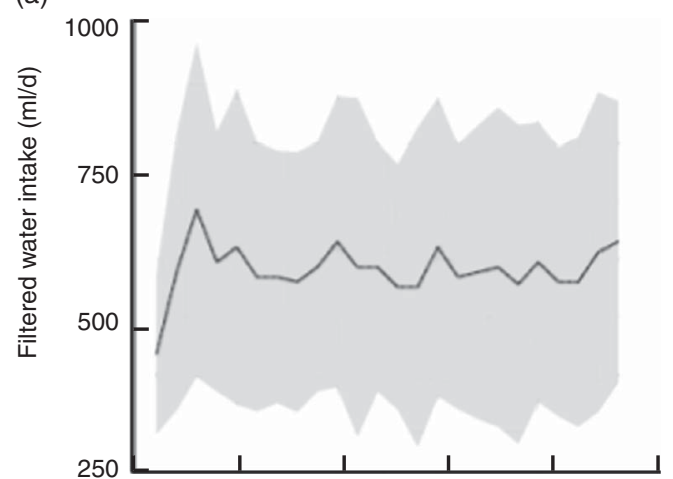

(c)

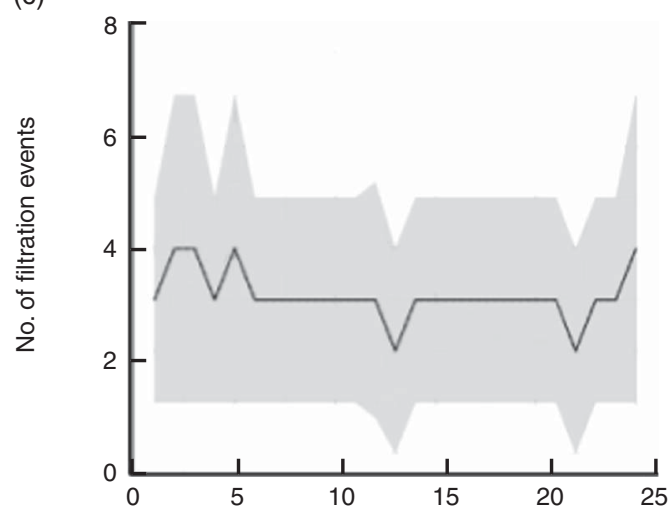

(b)

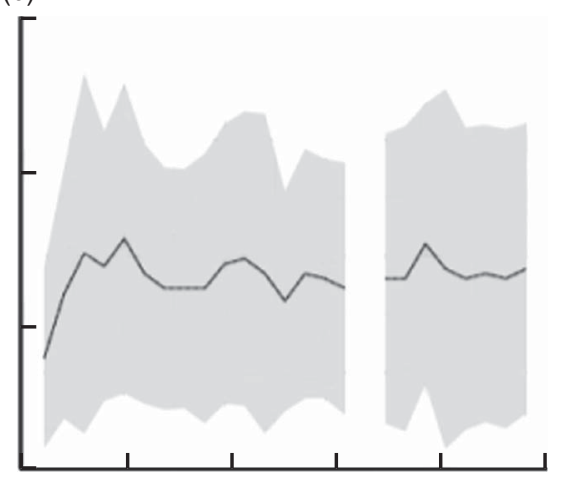

(d)

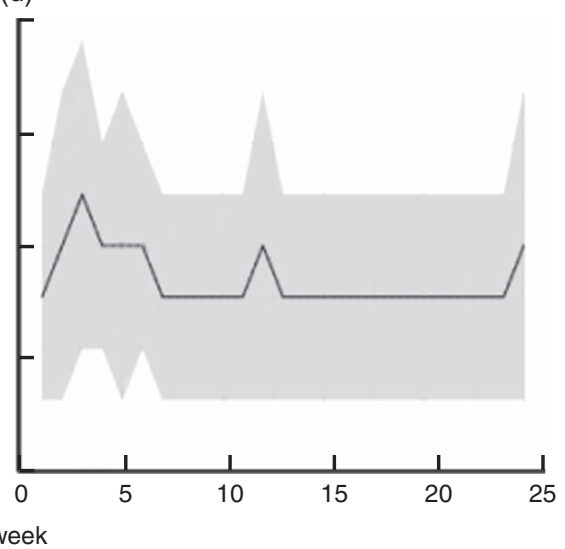

Fig. 2 Filtered water intake (a, b) and filter usage (c, d) over the study period, by treatment group (a and c, FW group; b and d, ZFW group), among children aged 2-6 years, rural western Kenya, February-August 2014. Solid line represents the median and the shaded area represents the interquartile range (FW, filtered water; ZFW, zinc-fortified filtered water)

Table 2 Zinc intake from the diet, filtered fortified water and filtered non-fortified water by children aged 2-6 years from rural western Kenya, February-August 2014

\begin{tabular}{|c|c|c|c|c|c|c|}
\hline & \multicolumn{3}{|c|}{ ZFW group } & \multicolumn{3}{|c|}{ FW group } \\
\hline & $n / N$ & Mean or Median & SD or IQR & $n / N$ & Mean or Median & SD or IQR \\
\hline Dietary $\mathrm{Zn}$ intake without filtered water $(\mathrm{mg} / \mathrm{d})^{\star}$ & $54 / 109$ & $6 \cdot 0$ & 1.7 & $55 / 109$ & 5.7 & 1.6 \\
\hline Filtered water intake $(\mathrm{ml} / \mathrm{d}) \dagger$ & $88 / 178$ & 450 & $598-675$ & $90 / 178$ & 471 & $300-718$ \\
\hline Water $\mathrm{Zn}$ concentration (mg/l)† & $74 / 150$ & $1.0^{\mathrm{a}}$ & $0.5-2.5$ & $74 / 150$ & $0.3^{\mathrm{b}}$ & $0.1-0.6$ \\
\hline Overall $\mathrm{Zn}$ intake from filtered water $(\mathrm{mg} / \mathrm{d}) \dagger$ & $88 / 178$ & $0.5^{a}$ & $0.3-0.6$ & $88 / 178$ & $0.0^{\mathrm{b}}$ & $0.0-0.1$ \\
\hline $\begin{array}{l}\text { Zn intake from filtered water }(\mathrm{mg} / \mathrm{d}) \text { : low intake group } \\
(<500 \mathrm{ml} / \mathrm{d}) \dagger\end{array}$ & $54 / 88$ & 0.4 & $0.3-0.5$ & - & - & - \\
\hline $\begin{array}{l}\text { Zn intake from filtered water }(\mathrm{mg} / \mathrm{d}) \text { : high intake group } \\
(\geq 500 \mathrm{ml} / \mathrm{d}) \dagger\end{array}$ & $34 / 88$ & 0.8 & $0.7-1 \cdot 0$ & - & - & - \\
\hline
\end{tabular}

ZFW, Zn-fortified filtered water; FW, filtered water; IQR, interquartile range.

${ }_{\mathrm{a}, \mathrm{b}}$ Median values within a row with unlike superscript letters were significantly different $(P<0.05)$ by the Mann-Whitney $U$ test.

${ }^{*}$ Values are mean and SD.

†Values are median and IQR.

In the current study, the target group comprised younger children (aged 2-6 years) who generally are more vulnerable to critical water quality and paediatric infections than school-aged children ${ }^{(7)}$; a difference that could explain the decrease in infections in the current study as compared with the study in Benin schoolchildren. Another difference could be that the pre-school Kenyan children almost exclusively consumed filtered water as this was available at home. In Benin, schoolchildren drank purified water only in school. Similar to our findings, daily $\mathrm{Zn}$ supplementation $(5 \mathrm{mg} / \mathrm{d}$ in $5 \mathrm{ml}$ sterile water) reduced incidence of diarrhoea and upper respiratory tract 


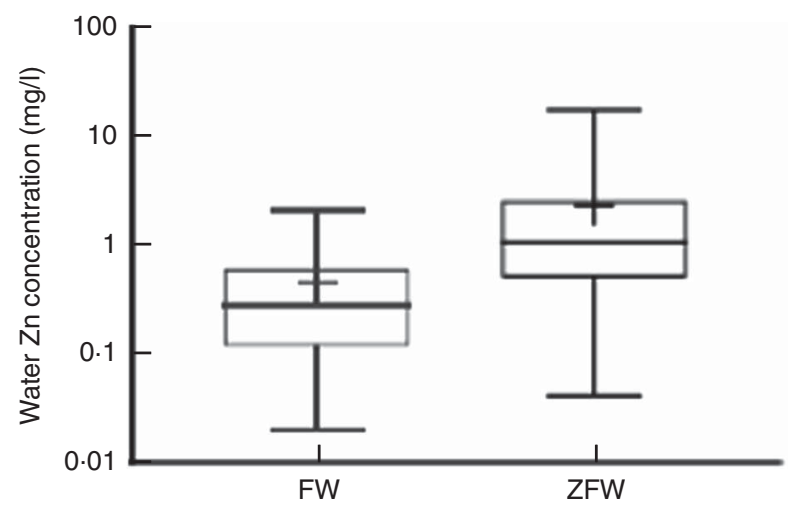

Fig. 3 Box-and-whisker plots of water zinc concentrations in samples collected in the households of the two treatment groups at four time points over the 6-month intervention period $\left(n_{\text {total }} 150\right)$, rural western Kenya, February-August 2014 . The bottom and top edge of the box represent the first and third quartiles (interquartile range); the line within the box represents the median; the ends of the bottom and top whiskers represent the minimum and maximum values; and the average value is marked with + . There was a significant difference in zinc concentrations between intervention (ZFW) and control households (FW; Mann-Whitney $U$ test, $P<0.05$ ). (FW, filtered water; ZFW, zinc-fortified filtered water)

infection in Tanzanian infants ${ }^{(23)}$, and comparable benefits of $\mathrm{Zn}$ supplementation on diarrhoea and acute respiratory infection have been observed in a systematic review ${ }^{(4)}$.
In contrast, we did not detect increase in the secondary outcome PZn and in the prevalence of Zn deficiency. PZn responds to intake but it is not a sensitive marker of $\mathrm{Zn}$ status, and a marker reflecting body $Z n$ pools is yet to be identified $^{(24)}$. A previous $\mathrm{Zn}$ supplementation study in $\mathrm{Zn}$ deficient children has shown improvement in clinical features of $\mathrm{Zn}$ deficiency such as linear growth and immune function with no change in $\mathrm{PZn}^{(25)}$, while several studies have shown improvements in growth indices in Zn-supplemented children with no increase in serum $\mathrm{Zn}^{(26,27)}$. These latter children were small-for-gestational age, stunted or malnourished at baseline. It could be that in nutritionally deficient children, functional response is higher due to a higher sequestration rate of $\mathrm{Zn}$ by tissues in need of $\mathrm{Zn}$. Furthermore, in a review to assess the therapeutic value of $\mathrm{Zn}$ supplementation in acute and persistent diarrhoea, the efficacy of $\mathrm{Zn}$ therapy on acute diarrhoea was not predicted by $\mathrm{PZn}^{(28)}$.

The current study was conducted in rural Kisumu in villages along Lake Victoria. The households are exposed daily to unclean water and the risk of Zn deficiency and infections was expected to be high. This was confirmed by the high prevalence of inflammation, Zn deficiency as well as anaemia at baseline. A high proportion ( $81 \cdot 1$ and $87.3 \%$ in the ZFW and FW group, respectively) of the children were below the WHO Estimated Average Requirement for

Table 3 Effect of the 6-month intervention (daily consumption of fortified or non-fortified filtered water) on plasma zinc and acute-phase protein concentrations and height-for-age Z-scores by treatment group in children aged 2-6 years from rural western Kenya, February-August 2014

\begin{tabular}{|c|c|c|c|c|c|c|c|}
\hline & \multicolumn{3}{|c|}{ ZFW group } & \multicolumn{3}{|c|}{ FW group } & \multirow[b]{2}{*}{$P^{*}$} \\
\hline & $n$ & Mean or Median & SD or IQR & $n$ & Mean or Median & SD or IQR & \\
\hline \multicolumn{8}{|c|}{ Uncorrected PZn concentration† ( $\mu \mathrm{g} / \mathrm{dl})$} \\
\hline Baseline & 84 & $65 \cdot 9$ & $10 \cdot 6$ & 90 & 63.5 & $12 \cdot 9$ & \\
\hline Midpoint & 81 & 68.7 & $11 \cdot 8$ & 81 & $69 \cdot 1$ & $14 \cdot 2$ & \\
\hline Endpoint & 79 & $64 \cdot 3$ & $10 \cdot 9$ & 84 & 65.5 & 11.8 & 0.11 \\
\hline \multicolumn{8}{|c|}{ Corrected PZn concentration†, $\ddagger(\mu \mathrm{g} / \mathrm{dl})$} \\
\hline Baseline & 82 & $68 \cdot 2$ & $10 \cdot 3$ & 84 & $64 \cdot 8$ & $13 \cdot 3$ & \\
\hline Midpoint & 80 & 71.0 & 11.7 & 81 & 72.8 & 14.5 & \\
\hline Endpoint & 79 & 67.4 & $10 \cdot 6$ & 84 & $68 \cdot 2$ & $12 \cdot 3$ & 0.14 \\
\hline \multicolumn{8}{|l|}{ CRP§ (mg/l) } \\
\hline Baseline & 82 & 2.4 & $0 \cdot 7-15 \cdot 0$ & 84 & 2.4 & $0.9-15 \cdot 0$ & \\
\hline Midpoint & 80 & 1.4 & $0.4-15.6$ & 81 & $2 \cdot 6$ & $0.8-12 \cdot 3$ & \\
\hline Endpoint & 79 & $3 \cdot 8$ & $0.8-33.4$ & 84 & $2 \cdot 1$ & $0.8-11.3$ & $0 \cdot 10$ \\
\hline \multicolumn{8}{|l|}{ AGP§ $(g / l)$} \\
\hline Baseline & 82 & $1 \cdot 1$ & $0.6-1.6$ & 84 & 1.0 & $0.8-1.6$ & \\
\hline Midpoint & 80 & 0.9 & $0.6-1.6$ & 81 & $1 \cdot 1$ & $0.6-1.6$ & \\
\hline Endpoint & 79 & 1.2 & $0.8-1.6$ & 84 & 0.9 & $0.6-1.5$ & 0.83 \\
\hline \multicolumn{8}{|l|}{ HAZ† } \\
\hline Baseline & 82 & -0.8 & 1.5 & 82 & -0.9 & 1.5 & \\
\hline Midpoint & 80 & $-1 \cdot 2$ & 1.4 & 79 & -0.9 & 1.5 & \\
\hline Endpoint & 77 & $-0 . \overline{8}$ & 1.4 & 79 & -0.9 & 1.4 & 0.97 \\
\hline
\end{tabular}

ZFW, Zn-fortified filtered water; FW, filtered water; IQR, interquartile range; PZn, plasma Zn; CRP, C-reactive protein; AGP, $a_{1}$-acid glycoprotein; HAZ, height-forage Z-score.

*Testing the time-by-treatment effect by linear mixed-effect models for continuous variables and generalized estimating equations binary logistic models for binary variables $(P<0.05)$.

†Values are mean and SD.

¥Corrected using the four-level inflammation correction factor approach. Participants were allocated to the reference group unless plasma CRP concentration was $>5 \mathrm{mg} / \mathrm{l}$ and/or plasma AGP was $>1 \mathrm{~g} / \mathrm{l}$ when they were allocated to the incubation (only CRP elevated), early convalescence (both CRP and AGP elevated) or late convalescence (only AGP elevated) groups.

$\S$ Values are median and IQR. 
Table 4 Effect of the 6-month intervention (daily consumption of fortified or non-fortified filtered water) on zinc status markers by treatment group in children aged 2-6 years from rural western Kenya, February-August 2014

\begin{tabular}{|c|c|c|c|c|c|}
\hline & \multicolumn{2}{|c|}{ ZFW group } & \multicolumn{2}{|c|}{ FW group } & \multirow[b]{2}{*}{$P^{\star}$} \\
\hline & $\%$ & $n / N$ & $\%$ & $n / N$ & \\
\hline \multicolumn{6}{|c|}{ Zn deficiency (uncorrected; \%) } \\
\hline Baseline & $42 \cdot 9$ & $36 / 84$ & $53 \cdot 3$ & $48 / 90$ & \\
\hline Midpoint & 43.2 & $35 / 81$ & $45 \cdot 7$ & $37 / 81$ & \\
\hline Endpoint & $50 \cdot 6$ & $41 / 79$ & $52 \cdot 4$ & $44 / 84$ & 0.51 \\
\hline \multicolumn{6}{|c|}{ Stunting prevalence $(\mathrm{HAZ}<-2 ; \%)$} \\
\hline Baseline & $15 \cdot 8$ & $13 / 82$ & 19.5 & $16 / 82$ & \\
\hline Midpoint & $20 \cdot 0$ & $16 / 80$ & $20 \cdot 2$ & $16 / 79$ & \\
\hline Endpoint & $18 \cdot 2$ & $14 / 77$ & $19 \cdot 0$ & $15 / 79$ & 0.88 \\
\hline
\end{tabular}

ZFW, Zn-fortified filtered water; FW, filtered water; HAZ, height-for-age Z-score.

${ }^{*}$ Testing the time-by-treatment effect by linear mixed-effect models for continuous variables and generalized estimating equations binary logistic models for binary variables $(P<0.05)$.

Table 5 Effect of the 6-month intervention (daily consumption of fortified or non-fortified filtered water) on the occurrence of common infectious morbidities in children aged 2-6 years, rural western Kenya, February-August 2014

\begin{tabular}{|c|c|c|c|c|c|c|c|c|c|c|c|c|c|c|}
\hline & \multicolumn{7}{|c|}{ ITT } & \multicolumn{7}{|c|}{ PP } \\
\hline & \multicolumn{2}{|c|}{$\begin{array}{l}\text { ZFW group } \\
\quad(n \text { 88) }\end{array}$} & \multicolumn{2}{|c|}{$\begin{array}{l}\text { FW group } \\
(n 90)\end{array}$} & \multirow[b]{2}{*}{$\mathrm{RR}^{*}$} & \multirow[b]{2}{*}{$95 \% \mathrm{Cl}$} & \multirow[b]{2}{*}{$P$} & \multicolumn{2}{|c|}{$\begin{array}{l}\text { ZFW group } \\
(n \text { 83) }\end{array}$} & \multicolumn{2}{|c|}{$\begin{array}{c}\text { FW group } \\
(n 84)\end{array}$} & \multirow[b]{2}{*}{$\mathrm{RR}^{*}$} & \multirow[b]{2}{*}{$95 \% \mathrm{Cl}$} & \multirow[b]{2}{*}{$P$} \\
\hline & $\%$ & $n_{\text {event }} / n_{\text {visit }}$ & $\%$ & $n_{\text {event }} / n_{\text {visit }}$ & & & & $\%$ & $n_{\text {event }} / n_{\text {visit }}$ & $\%$ & $n_{\text {event }} / n_{\text {visit }}$ & & & \\
\hline \multicolumn{15}{|c|}{ Morbidity per condition } \\
\hline Diarrhoea & 3.9 & $80 / 2063$ & 5.0 & $103 / 2088$ & 0.78 & $0.59,1.04$ & 0.09 & 3.6 & 73/2022 & $5 \cdot 0$ & $103 / 2043$ & 0.72 & $0.53,0.96$ & 0.025 \\
\hline $\begin{array}{l}\text { Cold with runny } \\
\text { nose }\end{array}$ & $29 \cdot 8$ & $615 / 2060$ & $32 \cdot 9$ & $687 / 2088$ & 0.91 & $0.83,0.99$ & 0.034 & $26 \cdot 6$ & $598 / 2019$ & $33 \cdot 3$ & $680 / 2043$ & 0.88 & $0.81,0.97$ & 0.011 \\
\hline Rapid breathing & $8 \cdot 1$ & $168 / 2062$ & $9 \cdot 0$ & $188 / 2087$ & 0.90 & $0.74,1.10$ & 0.32 & $8 \cdot 1$ & $163 / 2021$ & $9 \cdot 0$ & $184 / 2042$ & 0.89 & $0.73,1.10$ & 0.28 \\
\hline Cough & 27.0 & $562 / 2062$ & 29.0 & $610 / 2089$ & 0.93 & $0.85,1.03$ & 0.16 & 27.0 & $546 / 2021$ & 29.6 & $606 / 2044$ & 0.91 & $0.83,1.00$ & 0.06 \\
\hline Abdominal pain & 5.6 & $116 / 2060$ & 7.9 & $167 / 2091$ & 0.70 & $0.56,0.89$ & 0.003 & 5.5 & $112 / 2019$ & 8.1 & $165 / 2046$ & 0.69 & $0.54,0.87$ & 0.002 \\
\hline Fever & $25 \cdot 0$ & $520 / 2063$ & $26 \cdot 0$ & $550 / 2091$ & 0.96 & $0.86,1.06$ & 0.42 & $25 \cdot 3$ & $511 / 2022$ & $26 \cdot 4$ & $541 / 2046$ & 0.96 & $0.86,1.06$ & 0.39 \\
\hline Headache & $22 \cdot 0$ & $455 / 2058$ & 23.4 & $489 / 2090$ & 0.94 & $0.84,1.06$ & 0.32 & 22.0 & $446 / 2017$ & 23.5 & $480 / 2045$ & 0.94 & $0.84,1.06$ & 0.30 \\
\hline Sore throat & $5 \cdot 2$ & $107 / 2061$ & 5.8 & 122/2090 & 0.89 & $0.69,1.14$ & 0.36 & $5 \cdot 2$ & $105 / 2020$ & 5.9 & $121 / 2045$ & 0.88 & $0.68,1.13$ & 0.32 \\
\hline
\end{tabular}

ITT, intention to treat; PP, per protocol; ZFW, Zn-fortified filtered water; FW, filtered water.

Recall period was $2 \mathrm{~d}$ for diarrhoea only and 1 week for all other conditions assessed.

${ }^{*}$ Risk ratios $(\mathrm{RR})$ and $95 \% \mathrm{Cl}$ for disease incidence were calculated by means of contingency tables.

Zn intake without contribution of Zn-fortified water, suggesting elevated risk of zinc deficiency. At a fortification level of at least $1.0 \mathrm{mg} / \mathrm{l}$, the consumption of $500 \mathrm{ml}$ of fortified water daily contributed about $0.5 \mathrm{mg}$ additional $\mathrm{Zn} / \mathrm{d}$. This amount though seemingly low is highly bioavailable (approximately 65\%) when consumed away from meals ${ }^{(7)}$ and can contribute up to 36 and $31 \%$ of the WHO's set physiological requirements for absorbed $\mathrm{Zn}$ of children aged $2-3$ years $(0.83 \mathrm{mg} / \mathrm{d})$ and $4-6$ years $(0.93 \mathrm{mg} / \mathrm{d})$, respectively ${ }^{(2)}$. This may be particularly the case in this population, which has a diet rich in inhibitors of $\mathrm{Zn}$ absorption and an estimated low $\mathrm{Zn}$ bioavailability from the diet of $15 \%$.

The lack of an overall effect on PZn concentration and stunting could also have been due to the low dosage delivered by the fortification device. Trials on $\mathrm{Zn}$ fortification of cereals that have used fortification levels below $5 \mathrm{mg} / \mathrm{d}$ have shown mixed results. A recent review on $\mathrm{Zn}$ fortification trials (fortification levels ranged from 3.2 to $15 \mathrm{mg} / \mathrm{l}$ ) reported a significant impact on PZn concentration but a non-significant effect on growth ${ }^{(5)}$. Although the ZFW group reported lower morbidity, the inflammatory marker AGP was significantly higher in the ZFW group. A possible explanation may be that increased $\mathrm{Zn}$ intake resulted in a more effective immune response as reflected in an elevated AGP ${ }^{(29)}$. Supplementation with $\mathrm{Zn}$ has previously been shown to amplify markers of the acute-phase response, as shown by increased body temperature, cytokine concentrations, ceruloplasmin and IL-6 in human and animal studies ${ }^{(30,31)}$.

Our study has several strengths and limitations. It was a randomised controlled trial and there was a low dropout rate $(9.7 \%)$. We studied pre-school children, an age group particularly vulnerable to both poor sanitation and $\mathrm{Zn}$ deficiency, and therefore most likely to benefit from a household-based intervention. A limitation of the study was that although daily consumption of Zn-fortified water was associated with lower morbidity due to abdominal pain and upper respiratory tract infection, the study lacked statistical power to measure effects on growth or morbidity 
and hence these results should be interpreted with caution. Although active weekly surveillance was systematically performed in all study children, morbidity data were collected based on recall from the mother, a method that can introduce recall bias. We minimised this bias by carefully blinding the participating families and rigorously standardising data collection protocols. We conducted the study during the peak infection season; this may have increased our ability to detect an effect on infectious morbidity but also may have confounded our ability to detect a positive effect on PZn concentration, due to the higher variability in this marker elicited by the high prevalence of infection. Furthermore, we cannot exclude that a longer observation period would have allowed us to detect stronger effects on morbidity and significant effects on PZn. Nevertheless, PZn has been reported to react rapidly to changes in intake ${ }^{(32)}$. Kenya has adopted a national policy of $\mathrm{Zn}$ supplementation as first-line treatment for diarrhoea. Thus, a potential confounder in our study was the dispensing of $\mathrm{Zn}$ tablets by the local clinic to study children for treatment of diarrhoea. However, the ZFW and FW groups reported to have received $\mathrm{Zn}$ tablets on a comparable number of occasions (eleven and twelve, respectively) and PZn concentrations decline rapidly after supplementation is withdrawn ${ }^{(32)}$. Our findings suggest that when households are provided with a water purification filter, compliance is likely to decrease in the absence of external reinforcement. This trend was particularly evident at periods close to baseline, midpoint and endpoint (Fig. 2). Although the present study did not set out to investigate determinants of compliance to filter usage, a previous study has recommended a change in design of the filter to encourage and increase compliance ${ }^{(33)}$.

\section{Conclusion}

In conclusion, our results show that Zn-fortified water provided as a household intervention contributes to dietary $\mathrm{Zn}$ intake and may result in a decrease in reported childhood infections. This suggests a high public health potential of $\mathrm{Zn}$ fortification of water when integrated in water treatment and supply systems. Combining sanitation and nutritional interventions in public health programmes may be particularly beneficial in communities affected by both high rates of paediatric infections and nutritional deficiencies. More research is required concerning feasibility on a large scale and safety of the approach.

\section{Acknowledgements}

Financial support: Financial support for the study was provided by Vestergaard SA (Lausanne, Switzerland) and NUFFIC (Netherlands Organisation for International
Cooperation in Higher Education, The Hague). Vestergaard SA and NUFFIC had no role in the design, analysis or writing of this article. Conflict of interest: None. Authorship: P.K., V.G., I.D.B., D.M., P.A. and M.B.Z. designed the research; P.K., E.O., V.G., V.J. and D.M. conducted the effectiveness trial; P.A., I.D.B. and D.M. supervised the fieldwork; P.K. analysed data; P.K. wrote the first draft of the paper and all authors edited and approved the final version of the paper. Ethics of buman subject participation: This study was conducted according to the guidelines laid down in the Declaration of Helsinki and all procedures involving human subjects were approved by the Ethical Review Committee of Kenyatta National Hospital/Nairobi University (KNH-ERC/ A/335) and ETH Zurich Ethical Committee (EK 2013-N-31). Written informed consent was obtained from the head of household and caregiver on behalf of their children before the study commenced. The trial was registered at www. clinicaltrials.gov (NCT02162238).

\section{References}

1. Wessels RK, Singh MG \& Brown KH (2012) Estimating the global prevalence of inadequate zinc intake from national food balance sheets: effects of methodological assumptions. PLoS One 7, e50565.

2. Brown KH, Rivera JA, Bhutta Z et al. (2004) International zinc nutrition consultative group (IZiNCG) technical document \#1. Assessment of the risk of zinc deficiency in populations and options for its control. Food Nutr Bull 25, 1 Suppl. 2, S99-S203.

3. Young GP, Mortimer EK, Gopalsamy GL et al. (2014) Zinc deficiency in children with environmental enteropathy development of new strategies: report from an expert workshop. Am J Clin Nutr 100, 1198-1207.

4. Mayo-Wilson E, Junior JA, Imdad A et al. (2014) Zinc supplementation for preventing mortality, morbidity, and growth failure in children aged 6 months to 12 years of age. Cochrane Database Syst Rev issue 5, CD009384.

5. Das J, Kumar R, Bhutta Z et al. (2013) Systematic review of zinc fortification trials. Ann Nutr Metab 62, 44-56.

6. Hess SY \& Brown KH (2009) Impact of zinc fortification on zinc nutrition. Food Nutr Bull 30, 1 Suppl, S79-S107.

7. Galetti V, Kujinga P, Mitchikpè CES et al. (2015) Efficacy of highly bioavailable zinc from fortified water: a randomized controlled trial in rural Beninese children. Am J Clin Nutr 102, 1238-1248.

8. Kenya National Bureau of Statistics (2013) Kisumu County Multiple Indicator Cluster Survey 2011, Final Report. Nairobi: Kenya National Bureau of Statistics.

9. Moshfegh A, Raper N, Ingwersen L et al. (2001) An improved approach to 24-hour dietary recall methodology. Ann Nutr Metab 45, 156.

10. Gegios A, Amthor R, Maziya-Dixon B et al. (2010) Children consuming cassava as a staple food are at risk for inadequate zinc, iron, and vitamin A intake. Plant Foods Hum Nutr 65 , $64-70$.

11. Gibson R \& Ferguson E (1999) An Interactive 24-hour Recall for Assessing the Adequacy of Iron and Zinc Intakes in Developing Countries. Washington, DC: International Life Sciences Institute.

12. Broersen B (2014) Developing and evaluating standardised techniques for assessing filter usage in households and drinking water consumption of children in east Seme, Kenya. MSc Thesis, Wageningen University. 
13. International Zinc Consultative Group (2012) Practical Tips to Collect Blood in the Field for Assessment of Zinc Concentration. Davis, CA: IZINCG.

14. Erhardt JG, Estes JE, Pfeiffer CM et al. (2004) Combined measurement of ferritin, soluble transferrin receptor, retinol binding protein, and C-reactive protein by an inexpensive, sensitive, and simple sandwich enzyme-linked immunosorbent assay technique. J Nutr 134, 3127-3132.

15. World Health Organization (2011) Haemoglobin Concentrations for the Diagnosis of Anaemia and Assessment of Severity. Geneva: WHO.

16. Ramakrishnan R, Venkatarao T, Koya P et al. (1999) Influence of recall period on estimates of diarrhoea morbidity in infants in rural Tamilnadu. Indian J Public Health $\mathbf{4 3}$, 136-139.

17. World Health Organization (2013) Diarrhoeal Disease. Geneva: WHO.

18. Sehmi J (1993) National Food Composition Tables and the Planning of Satisfactory Diets in Kenya. Nairobi: Government Press.

19. US Department of Agriculture, Agricultural Research Service (2007) USDA Table of Nutrient Retention Factors, Release 6. Nutrient Data Laboratory Home Page. http://www.ars.usda. gov/ba/bhnrc/ndl (accessed September 2016).

20. National Research Council (1986) Nutrient Adequacy: Assessment Using Food Consumption Surveys. Report of the Sub-Committee on Criteria for Dietary Evaluation, Food and Nutrition Board, Commission of Life Sciences. Washington, DC: National Academy Press.

21. Hanley JA (2003) Statistical analysis of correlated data using generalized estimating equations: an orientation. Am J Epidemiol 157, 364-375.

22. World Health Organization (1996) Guidelines for DrinkingWater Quality, 2nd ed. vol. 2: Health Criteria and Other Supporting Information. Geneva: WHO.

23. McDonald CM, Manji KP, Kisenge R et al. (2015) Daily zinc but not multivitamin supplementation reduces diarrhea and upper respiratory infections in Tanzanian infants: a randomized, double-blind, placebo-controlled clinical trial. $J$ Nutr 145, 2153-2160.

24. King JC, Brown KH, Gibson RS et al. (2016) Biomarkers of nutrition for development (BOND) - zinc review. J Nutr 146, issue 4, 858S-885S.

25. Schlesinger L, Arevalo M, Arredondo S et al. (1992) Effect of a zinc-fortified formula on immunocompetence and growth of malnourished infants. Am J Clin Nutr 56, 491-498.

26. Friis H, Ndhlovu P, Mduluza T et al. (1997) The impact of zinc supplementation on growth and body composition: a randomized, controlled trial among rural Zimbabwean schoolchildren. Eur J Clin Nutr 51, 38-45.

27. Castillo-Durán C, Rodríguez A, Venegas G et al. (1995) Zinc supplementation and growth of infants born small for gestational age. J Pediatr 127, 206-211.

28. Patel A, Mamtani M, Dibley MJ et al. (2010) Therapeutic value of zinc supplementation in acute and persistent diarrhea: a systematic review. PLoS One 5, e10386.

29. Aydemir TB, Blanchard RK \& Cousins RJ (2006) Zinc supplementation of young men alters metallothionein, zinc transporter, and cytokine gene expression in leukocyte populations. Proc Natl Acad Sci U S A 103, 1699-1704.

30. Krones C, Klosterhalfen B, Fackeldey V et al. (2004) Deleterious effect of zinc in a pig model of acute endotoxemia. J Invest Surg 17, 249-256.

31. Braunschweig CL, Sowers M, Kovacevich DS et al. (1997) Parenteral zinc supplementation in adult humans during the acute phase response increases the febrile response. $J$ Nutr 127, 70-74.

32. Wessells KR, Jorgensen JM, Hess SY et al. (2010) Plasma zinc concentration responds rapidly to the initiation and discontinuation of short-term zinc supplementation in healthy men. $J$ Nutr 140, 2128-2133.

33. Galetti V (2014) Combining water treatment and zinc fortification against zinc deficiency and diarrhea in low-income settings. PhD Thesis, ETH Zurich. 